neural tube defect. But many questions remain to be resolved.

The Committee on Safety of Medicines may have to review its decision when new evidence has been accumulated because the data available were mainly from only one group-that of Smithells. Although the data have come from many centres from a wide geographical area, including parts of Britain with low and high risks for neural tube defects, ${ }^{2}$ critics have correctly emphasised the lack of randomised controls. ${ }^{3}$ An apparent protective effect might be caused by systematic bias in selecting controls: women who present early for supplementation might have a naturally lower risk of having fetuses with neural tube defects than controls, who are largely selected from women who are seen too late in pregnancy for supplementation (after neural tube closure at around 26 days from conception). The possibility of bias in selection has been re-examined by Smithell's group, who conclude that "periconceptional vitamin supplementation is associated with a significantly reduced rate" of neural tube defects, whatever the mechanism. ${ }^{4}$

Few would complain about the cost of giving Pregnavite Forte $\mathrm{F}$ to the small number of women at high risk of having fetuses with neural tube defects since it is cheap and the risks are small as it contains little more than an adequate diet should provide. About $90-95 \%$ of fetuses with neural tube defects develop, however, in women with no history to alert them to their risk. Consequently most pregnant women would need supplementation if most neural tube defects were to be prevented. The 700000 or so women who become pregnant each year in Britain should not be submitted to a measure that has not been independently assessed. It would also be an unwarranted waste of NHS resources.

The Medical Research Council is currently running a randomised double blind trial examining the efficacy of the different ingredients of Pregnavite Forte F (although not Pregnavite Forte $F$ itself) in women who have had a fetus with a neural tube defect. This trial has been criticised because the doses of the various components are different from Pregnavite Forte F, recruitment is from heterogeneous populations, and it is claimed to be ethically unsound to include women as getting "minerals only" who might thus be construed as untreated. ${ }^{5}$ All women are, however, counselled at recruitment, and it is surely ethical if a woman agrees to participate after she has understood that the value of vitamin supplementation is not fully proved and that she has a $25 \%$ chance of being given minerals only. Despite its critics, the Medical Research Council trial has recruited about half the women needed, is expected to report in about five years time, ${ }^{6}$ and is the best current prospect of new data.

It will still, however, leave open important questions. Can we assume that observations made on women at high risk are relevant to women in general? Equally important, might a weak teratogenic effect be shown by periconceptional vitamin supplementation of millions of women. Should we now be planning a new large scale trial to answer these questions? If so what supplements should we use and in what dosage? Although some believe that folic acid is the active ingredient, ${ }^{7}$ and there is experimental evidence in support, ${ }^{8}$ this is not yet generally accepted.

The first lesson to be learnt from this episode is never to embark on such trials without adequate controls. Secondly, with hindsight it was unwise to remove Pregnavite Forte F because the (welcome) decision to reinstate it has given the erroneous impression that its preventive powers have been independently proved. Thirdly, can the organisers of the
Medical Research Council trial consider ways to accelerate recruitment to the trial to ensure a more speedy conclusion? Five years may be too long to wait given the present controversy and the possibility of pre-emptive population supplementation.

RODNEY HARRIS

Professor of Medical Genetics,

University of Manchester,

St Mary's Hospital

Manchester M13 0JH

1 Smithells RW, Sheppard S, Schorah CJ, et al. Apparent prevention of neural tube defects by periconceptional vitamin supplementation. Arch Dis Child 1981;56:911-8.

Seller MJ, Nevin NC. Periconceptional vitamin supplementation and the prevention of neural tube defects in south-east England and Northern Ireland. $\mathcal{F}$ Med Genet 1984;21:325-30.

3 Wald NJ, Polani PE. Neural-tube defects and vitamins: the need for a randomized clinical trial. Br f Obstet Gynaecol 1984;91:516-23.

4 Wild J, Read AP, Sheppard S, et al. Arch Dis Child 1986;61:440-4.

5 Edwards JH. Spina bifida trials. Nature 1983;305:468.

6 Anonymous. An odd way to license a drug. [Editorial.]

Anonymous. An odd way to license a drug. [Editorial.] Lancet 1987;ii:376.

Laurence KM, James N, Miller MH, Tennant GB, Campbell H. Double-blind randomized controlled trial of folate treatment before conception to prevent recurrence of neural tube defects. BrMed F 1981;282:1509-11.

8 Yates JRW, Ferguson-Smith MA, Shenkin A, Guzman-Rodriguez R, White M, Clark BJ. Is disordered folate metabolism the basis for the genetic predisposition to neural tube defects? Clin Genet 1987;31:279-87.

\section{Glasnost on pesticides}

One of the many consequences of last year's general election was the curtailment of the House of Commons Agriculture Committee's inquiry into the effects of pesticides on human health. Unfortunately, the committee had insufficient time to consider and agree an account of its deliberations before the dissolution of parliament. A draft report by the chairman has, however, been published ${ }^{1}$ and, although lacking the authority of consensus, should stimulate debate on its main conclusion - the need for more stringent and open evaluation of the hazards posed by agricultural chemicals.

The regulation of pesticides is vested mainly in the Ministry of Agriculture, Fisheries, and Food (MAFF) and its advisory committee on pesticides, although other agencies, such as the Health and Safety Executive, play a part in enforcing their safe handling. The report criticises the ministry for complacency, concluding that safety cannot be assumed merely from the absence of observed harmful effects. Rather the onus should be on the agrochemical industry to prove that its products are safe beyond reasonable doubt. Meanwhile those responsible for clearance of the products (the report recommends that control should pass from the Ministry of Agriculture to the Health and Safety Executive) must convince the public that they have the resources, knowledge, and independence to investigate potential health risks, and they must do so in a more open way. To this end the collection of epidemiological data must be improved. The report calls for a centralised system to coordinate all reports of pesticide poisoning and for more research into the long term effects of pesticide exposure, particularly in agricultural workers. In the laboratory the emphasis should shift from increasing numbers of routine tests to finding out more about mechanisms of toxicity.

The wording of the report is somewhat misleading. Safety is not an absolute that can be proved: research can only narrow the range of uncertainty surrounding risk estimates. Nevertheless, the requirement for stronger evidence of safety, particularly once a product is on the market, would be 
an important change. It is in the re-evaluation of chemicals, after they have been cleared for commercial use, that the current system is most lacking. In the United States and Canada, both of which were visited by the committee, pesticides must be relicensed every five years, and programmes to reassess "older" compounds are in progress.

The call for more epidemiological research into the long term effects of pesticides may not meet with universal enthusiasm. Because of the difficulties in unravelling complex patterns of past exposure and the rarity of many of the diseases that may be increased by pesticides, studies often fail to produce clear cut results. They do, however, influence regulatory decisions, and scientists must respond to the public demand for information. In the long term the task of the epidemiologist will be made easier if the report's recommendation of a standard record system for pesticide users is adopted.

Much emphasis is placed on the need for more openness in evaluating pesticides. Experience in North America suggests that concern for protecting trade secrets has been exaggerated, at least in relation to health and safety data. The dissemination of information about efficacy must also pose a threat to commercial security, but without it risks cannot be weighed against benefits. The report says little on this important subject. Perhaps with adequate protection of patients a fair arrangement for the release of data could be agreed.

In addition to its main theme the report makes several peripheral recommendations. Some-for example, the suggestion that chemicals with suspected (although not proved) chronic health effects should carry a government warningare fraught with practical difficulties. Others, such as the proposals for childproof packing of more toxic products, standards for protective clothing, and encouragement of improved methods of pesticide application, seem eminently sensible.

Epidemiologist,

MRC Environmental Epidemiology Unit,

Southampton General Hospital,

Southampton SO9 4XY

1 House of Commons Agriculture Committee. The effects of pesticides on human health. Vol 1 . London HMSO, 1987.

\section{Partnership for health: voluntary organisations and the NHS}

The government's recent attempts to encourage health authorities to support and cooperate more with voluntary organisations have met with some scepticism. Doctors and others question the role of the voluntary sector, managers are wary of the additional costs, and trades unions fear the spectre of volunteers as alternative cheap labour-a concern shared by the voluntary organisations themselves. All parties have reason to be cautious, but many of their worries arise because one does not know enough about the other's roles. Thus health authorities fail to recognise the diversity of voluntary organisations, whose activities extend from self help and raising funds to providing services and campaigning. In turn the often poor understanding by the voluntary organisations of National Health Service bureaucracy limits their ability to achieve a successful liaison.

Does health care in Britain stand to gain from more cooperation between the statutory and voluntary sectors? A recent report from a group of health authority and voluntary sector representatives believes that it does. ${ }^{1}$ In its view the voluntary organisations can complement the NHS by responding to local needs such as those of the minority ethnic groups; they can fill gaps in services by raising extra funds or redirecting public spending from bodies such as the Housing Corporation; they can provide a channel of communication for consumers' views to the health authority; and they can help promote health through activities which improve the environment and lifestyles. Nevertheless, perhaps the greatest asset of the voluntary organisations is their capacity to innovate, a tradition that goes back way before the National Health Service. Recent examples include the hospice movement, respite care, housing for the mentally handicapped, and rural transport schemes-topics in which statutory services and the professions have usually shown little or no interest.

Given these potential advantages, why have most health authorities and voluntary organisations not formed productive partnerships? The lack of understanding of each other's organisation and objectives appears to be the principal reason. The disparate and everchanging nature of the voluntary sector may be bewildering for a health authority seeking cooperation. Conversely, the bureaucracy of the health authority, in which no easily identifiable contact exists for voluntary organisations, contributes to the problem. Clearly many obstacles can be removed, or at least reduced, by simple administrative changes. In addition, to avoid recriminations later, both parties need first to consider the type of partnership they wish to create and to make explicit their expectations.

Broadly speaking there are two types of partnership: consultative and financial. The former provides voluntary organisations with a voice in planning and managing health services and health authorities with access to specialised and local knowledge. Financial partnership may consist either of "arms length" support, in which a voluntary organisation receives a general grant, or contractual agreements, in which a specific service is provided for the health authority on an agency basis. In 1984-5 financial support in England and Wales was about $£ 10 \mathrm{~m}$, or less than $0.01 \%$ of NHS expenditure-a figure that many voluntary organisations are seeking to increase. Increasing their financial dependence on the statutory sector in this way might, however, threaten a major asset-independence. In addition, any financial support from health authorities will inevitably be subject to the same "value for money" considerations that affect all NHS spending. Voluntary organisations might find themselves having to replace their own criteria with those of the health authority. Hence both partners need to proceed with caution, making their own motives and objectives clear from the outset. But the potential rewards are considerable.

NiCK BLACK

Senior Lecturer in Community Medicine,

Department of Community Health,

London School of Hygiene and Tropical Medicine,

London WCIE 7HT

1 National Association of Health Authorities/National Council for Voluntary Organisations Joint Working Party. Partnerships for health. Birmingham: National Association of Health Authorities, 1987. 